\title{
Pizotifen inhibits the proliferation and invasion of gastric cancer cells
}

\author{
YING JIANG, WEI WANG, XI WU and JIHUA SHI \\ Department of Gastroenterology, National Center of Gerontology, \\ Beijing Hospital, Beijing 100730, P.R. China
}

Received November 14, 2018; Accepted July 7, 2019

DOI: $10.3892 /$ etm.2019.8308

\begin{abstract}
Gastric cancer is the fifth most common malignancy and the third highest cause of cancer-associated mortality worldwide. Therefore, research on the pathogenesis of gastric cancer is of utmost importance. It has been reported that aberrant activation of the $\mathrm{Wnt} / \beta$-catenin signaling pathway is involved in the occurrence and development of gastric cancer. In the present study, it was found that pizotifen could inhibit the viability of gastric cancer cell lines MNK45 and AGS cells in a dose-dependent manner. Pizotifen treatment suppressed cell migration and invasion in MNK45 and AGS cells, whilst also inducing apoptosis. Western blot analysis demonstrated that pizotifen blocked the expression of Wnt3a, $\beta$-catenin and N-cadherin, whilst increasing E-cadherin expression. In addition, BML-284, a pharmacological Wnt signaling activator, partially reversed the changes in the expression levels of $\beta$-catenin, $N$-cadherin and E-cadherin in MNK45 and AGS cells induced by pizotifen. Collectively, these findings suggested that pizotifen demonstrates potential as a novel anti-cancer drug for the treatment of gastric cancer by inhibiting the $\mathrm{Wnt} / \beta$-catenin pathway.
\end{abstract}

\section{Introduction}

Gastric cancer is currently the third highest cause of cancer mortality among all malignancies worldwide (1). In recent years, the overall incidence and mortality of gastric cancer has been decreasing due to control of risk factors and the development of gastric cancer screening (2). However, the burden of gastric cancer remains critical due to the large population base and an increasingly aging population (3). In China, the incidence of gastric cancer and associated deaths accounts for

Correspondence to: Dr Wei Wang, Department of Gastroenterology, National Center of Gerontology, Beijing Hospital, 1 Da Hua Road, Dongdan, Beijing 100730, P.R. China

E-mail: wangv7980@163.com

Key words: pizotifen, gastric cancer, Wnt signaling, epithelialmesenchymal transition $\sim 50 \%$ of all gastric cancer cases in the world (4). This may be due to the higher proportion of advanced gastric cancer cases upon diagnosis. Therefore, investigations into the pathogenesis of gastric cancer may reveal biomarkers that can be used for early diagnosis and treatment.

The Wnt signaling pathway, named after the wingless and Int-1 genes (5), performs a variety of different functions, including wide involvement in embryonic development, tissue homeostasis and cell carcinogenesis (6). It is typically divided into the canonical and non-canonical signaling pathways, of which the canonical pathway (Wnt/ $\beta$-catenin) is the more well-known pathway and is highly conserved throughout the evolutionary process (7). Previous studies have demonstrated that the $\mathrm{Wnt} / \beta$-catenin signaling pathway serves a key role in regulating cell proliferation, maintenance of stem cell characteristics and homeostasis of normal gastric mucosa (8-10). In particular, it has been reported that activation of the Wnt/ $\beta$-catenin signaling cascade is found in $>30 \%$ of gastric cancer cases $(11,12)$. Indeed, evidence is accumulating showing that Wnt3a, one member of the Wnt family, has the ability to either promote or inhibit cancer progression via the canonical Wnt/ $\beta$-catenin signaling pathway, depending on the type of cancer (13).

$\beta$-catenin is a multifunctional protein, which was initially found to bind to E-cadherin-binding protein and participate in cell adhesion (14). E-cadherin is not only a key member of Wnt signaling pathway, but also a critical epithelial marker of epithelial-mesenchymal transition (EMT) (15). EMT refers to the process whereby epithelial cells transform into mesenchymal phenotype cells, resulting in enhanced cell motility and invasiveness. EMT is one of the key initiation events for tumor metastasis and has a crucial role in the invasion and metastasis of cancers, including gastric cancer (16-18). Therefore, increasing research has considered EMT as an effective therapeutic target in cancer treatment (19). Research over the past decade has mainly focused on searching for novel anticancer agents and reassessing known drugs that have been used in other diseases to uncover any potential anti-tumor effects (20). One of those, pizotifen, also known as 4-(1-methyl-4-piperidylidine)-9,10-dihydro-4H-benzo-(4,5) -cyclohepta(1,2)-thiophene, is a potent serotonin or 5-hydroxytryptamine $(\mathrm{HT})_{2}$ receptor antagonist (21). Pizotifen is primarily indicated for the prevention of vascular headaches (22). It has been previously reported that serotonin $5-\mathrm{HT}_{2 \mathrm{~A}}$ receptor antagonists, such as ritanserin, can inhibit cell viability and promote cell 
apoptosis in colorectal cancer cells (23). However, the effect of pizotifen on cancer growth and metastasis remains unknown.

In the present study, it was found that pizotifen inhibited the viability, migration and invasion of gastric cancer whilst inducing cell apoptosis. The Wnt/ $\beta$-catenin-epithelial-mesen chymal transition (EMT) signaling pathway may be involved in this process. These results suggested that pizotifen could potentially be a new therapeutic agent for the treatment of gastric cancer and warrants further assessment in future clinical studies.

\section{Materials and methods}

Reagents and antibodies. Pizotifen was purchased from MedChemExpress and its molecular structure is shown in Fig. 1A. The primary antibodies against Wnt3a (cat. no. ab28472; dilution, 1:1,000), active-caspase-3 (cat. no. ab2302; dilution, 1:1,000) were purchased from Abcam, and the primary antibodies against Cyclin D-1 (cat. no. 60186-1-lg; dilution, 1:1,000), Bax (cat. no. 50599-2-lg; dilution, 1:1,000), Bcl-2 (cat. no. 12789-1-AP; dilution, 1:1,000) and $\beta$-tubulin (cat. no. 10094-1-AP; dilution, 1:1,000) were purchased from ProteinTech Group, Inc. Primary antibodies against $\beta$-catenin (cat. no. 9562; dilution, 1:1,000), E-cadherin (cat. no. 14472; dilution, 1:1,000) and N-cadherin (cat. no. 4061; dilution, 1:1,000) were purchased from Cell Signaling Technology, Inc. Both secondary antibodies (horseradish peroxidase conjugated anti-rabbit, cat. no. SA00001-15; anti-mouse, cat. no. SA00001-1; both dilutions, 1:5,000) were purchased from ProteinTech Group, Inc. BML-284, a selective Wnt activator, was purchased from MedChemExpress. Unless specifically indicated, all other reagents were obtained from Sigma-Aldrich (Merck KGaA).

Cell culture and treatment. Human gastric cancer cell lines MNK45 and AGS were obtained from the Type Culture Collection of the Chinese Academy of Sciences. The cell lines were cultured in DMEM containing 10\% FBS (Gibco; Thermo Fisher Scientific, Inc.), penicillin (100 U/ml), and streptomycin $(100 \mathrm{mg} / \mathrm{ml})$, and were maintained in a humidified atmosphere $(95 \%)$ at $37^{\circ} \mathrm{C}$ under $5 \% \mathrm{CO}_{2}$. Cells in the logarithmic growth phase were treated with different concentrations of pizotifen $(10,20$ and $40 \mu \mathrm{M})$ or BML-284 $(10 \mu \mathrm{M})$ alone or co-treated with pizotifen $(20 \mu \mathrm{M})$ and BML-284 $(10 \mu \mathrm{M})$. The cells were treated for varying time periods, including 0, 24, 48 and $72 \mathrm{~h}, 0.1 \%$ DMSO was used as negative control.

Cell viability assay. The Cell Counting Kit-8 (CCK-8) assay was performed according to the manufacturer's protocol (Beijing Solarbio Science \& Technology Co., Ltd.). Cells were seeded into 96 -well plates at a density of $1 \times 10^{3}$ cells/well and cultured overnight to allow for adherence. Cultures were subsequently treated with different concentrations of pizotifen $(10,20$ and $40 \mu \mathrm{M})$. DMSO $(0.1 \%)$ was used as the negative control. The cells were then cultured for 3 days and measurements were obtained every $24 \mathrm{~h}$. When the cells were measured, CCK- 8 solution ( $10 \mu \mathrm{l} /$ well) was added to each well and incubated for an additional $1.5 \mathrm{~h}$ at $37^{\circ} \mathrm{C}$. The final optical density was measured at a wavelength of $450 \mathrm{~nm}$ to estimate cell viability in the different treatment groups. Each experiment was performed in triplicate.

Wound healing assay. Cells were first seeded into six-well plates at a density of $5 \times 10^{5}$ cells/well and incubated overnight at $37^{\circ} \mathrm{C}$. The following day, when cells had reached $\sim 95-100 \%$ confluency, wounds were generated using pipette tips. After being scratched with the pipettes, the cells were cultured in serum-free medium supplemented with 10 or $20 \mu \mathrm{M}$ pizotifen or DMSO for $24 \mathrm{~h}$. The wounds were photographed using a light microscope (magnification, x40) and analyzed using ImageJ software v1.8.0 (National Institutes of Health). The percentage wound closure was calculated using the mathematical equation: Percentage wound closure $(\%)=\left(\mathrm{A}_{0}-\mathrm{A}_{\mathrm{t}}\right) / \mathrm{A}_{0} \times 100 \%$, where $\mathrm{A}_{0}$ is the initial wound area, and $A_{t}$ is the wound area at $0,24 \mathrm{~h}$ post-treatment.

Western blot analysis. Total protein was extracted from the cell cultures according to instructions from radioimmunoprecipitation assay Lysis Buffer (CWBIO Tech). Protein concentration was quantified using an Enhanced Bicinchoninic Acid Protein Assay kit. A total of $20 \mu \mathrm{g}$ protein from each sample were separated by $10 \%$ SDS-PAGE and then transferred to PVDF membranes (Bio-Rad Laboratories, Inc.). The membranes were incubated in blocking buffer [5\% non-fat milk dissolved in TBS with Tween-20 (TBST)] at room temperature for 1-h and then probed at $4^{\circ} \mathrm{C}$ overnight with primary antibodies (dilution, 1:1,000). The membranes were subsequently rinsed with TBST and incubated with horseradish peroxidase-conjugated secondary antibodies $(1: 5,000)$ for 1 -h at room temperature. The blots were visualized using the enhanced chemiluminescence detection kit (Beyotime Institute of Biotechnology) and analyzed using the Quantity One 1-D software v4.6.7 (Bio-Rad Laboratories, Inc.). Each experiment was repeated at least three times.

Apoptosis assay. Cells $\left(5 \times 10^{5}\right)$ pretreated with $20 \mu \mathrm{M}$ pizotifen or $0.1 \%$ DMSO were double-stained with fluorescein isothiocyanate-conjugated Annexin $\mathrm{V}(25 \mathrm{mg} / \mathrm{ml})$ and propidium iodide (PI; $50 \mathrm{mg} / \mathrm{ml}$ ) at $4^{\circ} \mathrm{C}$ for $15 \mathrm{~min}$ according to the manufacturer's protocol (4A Biotech Co., Ltd.), and then washed and analyzed using a BD FACSCalibur flow cytometry system (BD Biosciences). The obtained data was analyzed using FlowJo software v7.6.1 (FlowJo LLC).

Transwell assays. For the Transwell migration assay, $5 \times 10^{3}$ cells pretreated with pizotifen or BML-284 were seeded into the upper sections of the non-coated 96-well inserts (pore size, $8 \mu \mathrm{m}$; Corning, Inc.). For the invasion assay, Matrigel (BD Biosciences) was thawed at $4^{\circ} \mathrm{C}$ and diluted in serum-free medium at a ratio of 1:6, then added to the upper chamber of the Transwell chamber and maintained at $37^{\circ} \mathrm{C}$ for $4-6 \mathrm{~h}$. A total of $1 \times 10^{5}$ cells were seeded into the top chamber of 24 -well inserts with $8 \mu \mathrm{m}$ pore size and Matrigel-coated membranes. In both assays, cells were diluted in medium without FBS and seeded into the top chamber, whereas medium containing 10\% FBS were introduced into the lower chamber in order to establish a chemoattractant gradient. Cells were incubated for $24 \mathrm{~h}$, fixed with $4 \%$ paraformaldehyde at room temperature for $30 \mathrm{~min}$, and stained with $0.1 \%$ crystal violet solution (Sigma-Aldrich; 
A<smiles>CN1CCC(=C2c3ccccc3CCc3sccc32)CC1</smiles>

Pizotifen

$\mathrm{C} 19 \mathrm{H} 21 \mathrm{NS}$
B

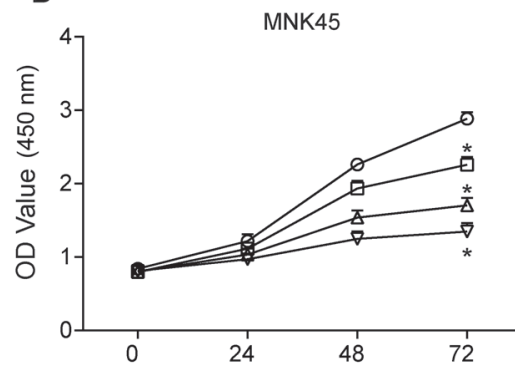

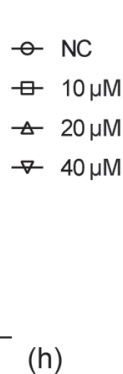

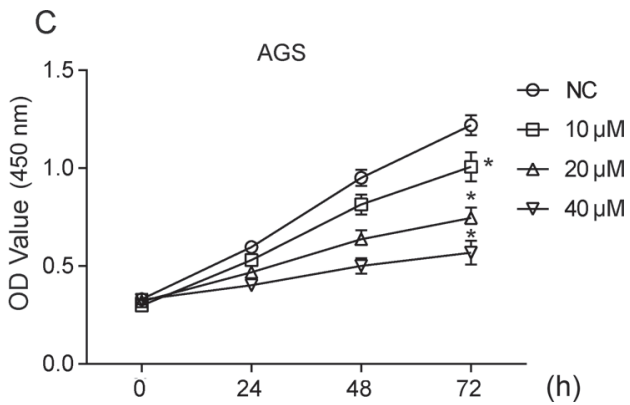

Figure 1. Pizotifen inhibits the cell viability of gastric cancer cells. (A) The chemical structure of pizotifen. (B) MNK45 and (C) AGS cells were treated with different concentrations of pizotifen $(0,10,20$ or $40 \mu \mathrm{M})$ for 24,48 and $72 \mathrm{~h}$. Cell viability was assessed using a Cell Counting Kit- 8 assay. Data are expressed as the mean \pm SD from three independent experiments. ${ }^{*} \mathrm{P}<0.05$ vs. NC. NC, negative control; OD, optical density.

Merck $\mathrm{KGaA}$ ) at room temperature for $20 \mathrm{~min}$. Then, 5 microscopic fields were used to count and photograph the stained cells under a light microscope (magnification, x100).

Statistical analysis. Experimental data are presented as the mean \pm SD. All statistical analysis was performed using SPSS 13.5 (SPSS, Inc.). Student's t-test and one-way ANOVA followed by Tukey's posthoc analysis were performed. $\mathrm{P}<0.05$ was considered to indicate a statistically significant difference.

\section{Results}

Pizotifen inhibits the viability of gastric cancer MNK45 and AGS cells. A CCK8 assay was carried out to determine the effect of pizotifen on the viability of gastric cancer cell lines MNK45 and AGS. As shown in Fig. 1B, pizotifen treatment of $48 \mathrm{~h}$ or $72 \mathrm{~h}$ significantly inhibited the viability of MNK45 cells in a dose-dependent manner $(\mathrm{P}<0.05)$. Similarly, pizotifen also inhibited the viability of AGS cells (Fig. 1C).

Pizotifen inhibits MNK45 and AGS cells migration and invasion. Wound-healing and Transwell assays were performed to investigate whether pizotifen affects the migratory and invasive properties of gastric cancer cells. Since 10 and $20 \mu \mathrm{M}$ pizotifen both caused appropriate inhibitory effect on MNK45 and AGS cells, whilst $40 \mu \mathrm{M}$ pizotifen caused increased cell death, 10 and $20 \mu \mathrm{M}$ of pizotifen were used in the rest experiments. As shown in Fig. 2A, 10 and $20 \mu \mathrm{M}$ pizotifen both led to a significant decrease in the migratory abilities of MNK45 cells in a dose-dependent manner $(\mathrm{P}<0.05)$. A similar inhibitory effect of pizotifen was observed in AGS cells ( $\mathrm{P}<0.05$; Fig. 2B). Moreover, the results of the Transwell assay further suggested that the migratory abilities of MNK45 and AGS cells were significantly inhibited following treatment with pizotifen $(\mathrm{P}<0.05$; Fig. $3 \mathrm{~A}-\mathrm{C})$. In addition, the invasive abilities of MNK45 and AGS cells treated with pizotifen were significantly reduced $(\mathrm{P}<0.05$; Fig. 3D-F). Furthermore, the data showed that BML-284, a selective Wnt signaling activator that has been revealed to induce $\beta$-catenin in vitro (24), significantly increased the migration and invasion of both MNK45 and AGS cells (both $\mathrm{P}<0.05$; Fig. 3), and partially restored the migratory and invasive abilities of MNK45 and AGS cells inhibited by pizotifen ( $\mathrm{P}<0.05$; Fig. 3).
Pizotifen induces the mitochondrial-mediated apoptosis of MNK45 and AGS cells. Annexin V-FITC/PI assay was performed to investigate whether pizotifen inhibited the growth of gastric cancer cells by triggering apoptosis. As shown in Fig. 4A, pizotifen $(20 \mu \mathrm{M})$ significantly enhanced cell apoptosis in both MNK45 and AGS cells (both $\mathrm{P}<0.01$ ) compared with the NC group (Fig. 4A). To further determine the mechanism of pizotifen-induced apoptosis, western blot analysis was performed to detect the expression of proteins associated with the mitochondrial apoptotic pathway in MNK45 and AGS cells treated with pizotifen for $48 \mathrm{~h}$ (Fig. 4B). The data demonstrated that the expression of the anti-apoptotic protein $\mathrm{Bcl}-2$ was significantly reduced in pizotifen-treated cells, whereas the expression of pro-apoptotic proteins Bax and active caspase-3 were significantly increased $(\mathrm{P}<0.05$; Fig. 4B). These data indicated that pizotifen may induce the apoptosis of gastric cancer cells via the intrinsic apoptotic pathway, specifically the Bax/Bcl-2 and caspase cascade.

Pizotifen downregulates the Wnt/ $\beta$-catenin-EMT signaling pathway in MNK45 and AGS cells. The ability of pizotifen to inhibit the Wnt/ $\beta$-catenin signaling pathway in MNK and AGS cells was investigated using western blot analysis. Pizotifen treatment significantly reduced the expression of Wnt3a and $\beta$-catenin in a dose-dependent manner in MNK45 and AGS cells $(\mathrm{P}<0.05$; Fig. 5A). In addition, the expression of the epithelial marker E-cadherin was significantly upregulated by pizotifen treatment in MNK45 and AGS cells, while the expression of the mesenchymal marker $\mathrm{N}$-cadherin was significantly downregulated $(\mathrm{P}<0.05$; Fig $5 \mathrm{~A})$, suggesting that pizotifen regulated the expression of EMT markers proteins in a dose-dependent manner. This suggested that pizotifen can suppress the Wnt/ $\beta$-catenin-EMT signaling pathway in MNK45 and AGS cells.

Wnt/ $\beta$-catenin-EMT signaling pathway may play a role in the anti-invasive effect of pizotifen. To further investigate the mechanism of action of pizotifen in the inhibition of gastric cancer cell invasion, BML-284 was used. It was found that the expression of $\beta$-catenin was significantly upregulated in MNK45 and AGS cells following BML-284 treatment compared with the NC group (Fig. 5B). In the presence of pizotifen, BML-284 treatment also partially restored $\beta$-catenin expression compared with the pizotifen-only group (Fig. 5B). 

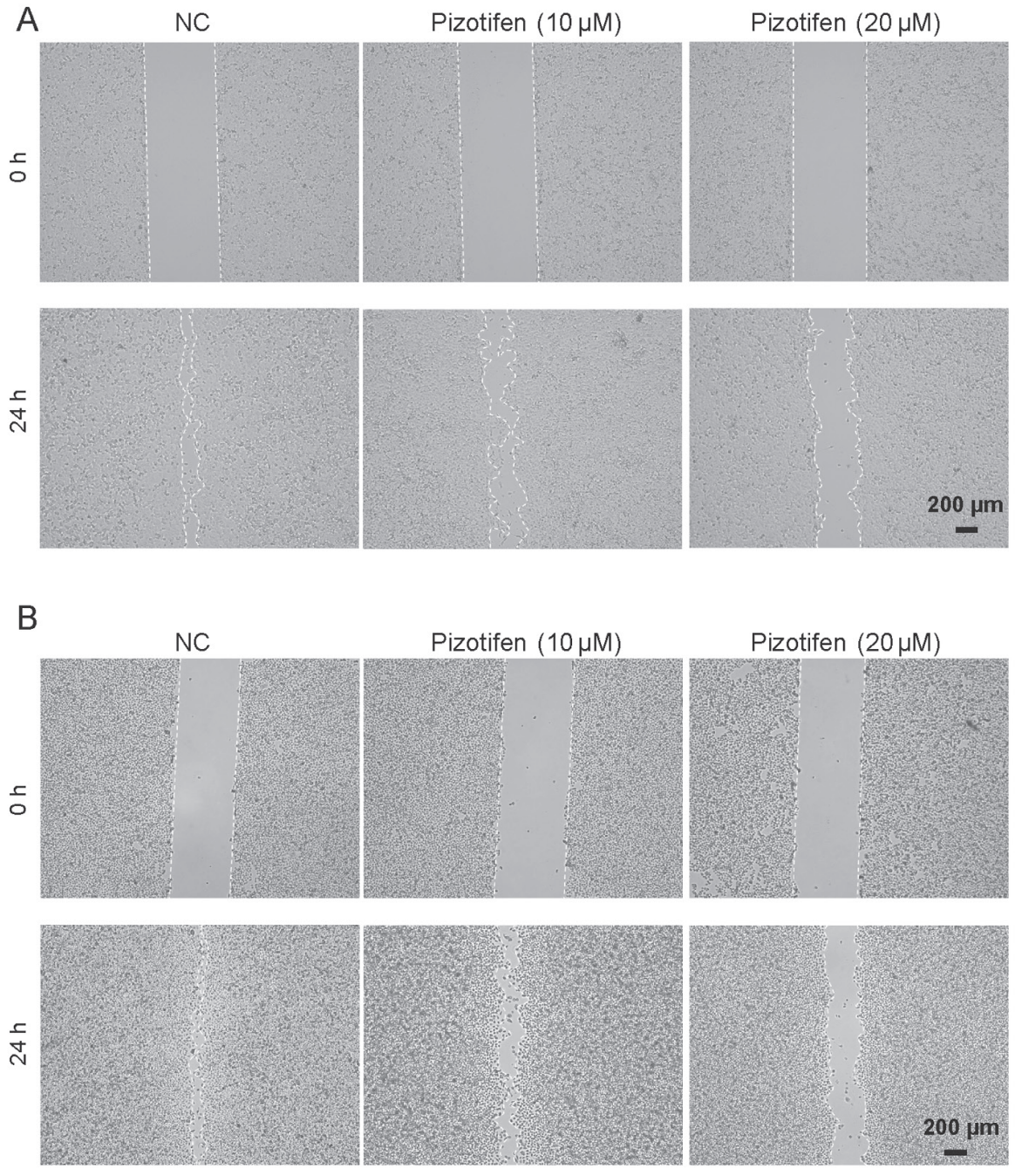
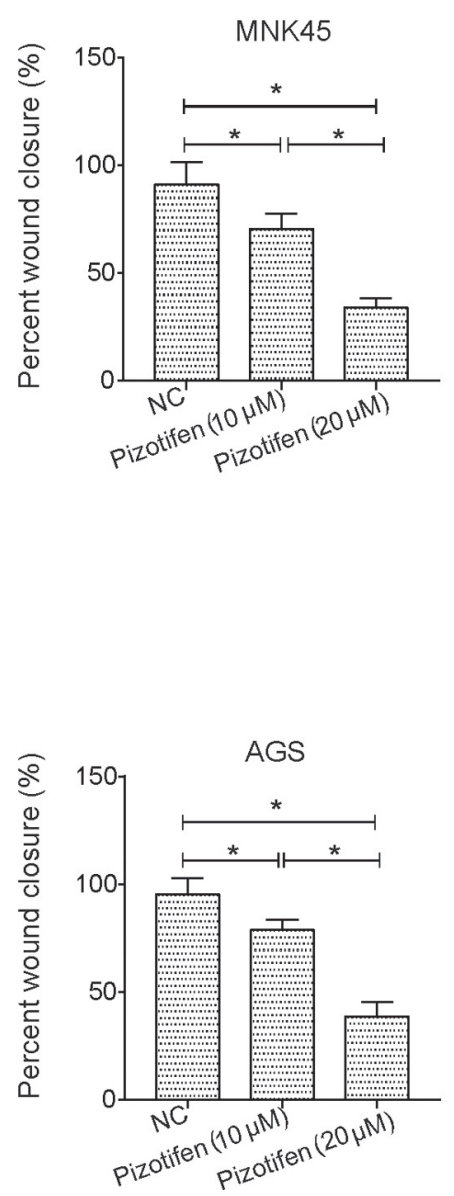

Figure 2. Pizotifen inhibits MNK45 and AGS cell migration. (A) MNK45 and (B) AGS cells were treated with two concentrations of pizotifen (10 and $20 \mu \mathrm{M})$ and a wound healing assay was performed to assess the migratory abilities of the two cell lines over $24 \mathrm{~h}$. Scale bar, $200 \mu \mathrm{m}$. Data are expressed as the mean \pm SD from three independent experiments. ${ }^{*} \mathrm{P}<0.05$ with comparisons indicted by lines. NC, negative control.

In addition, BML-284 treatment partially reversed the effects induced by pizotifen on E-cadherin and $\mathrm{N}$-cadherin expression in MNK45 and AGS cells compared with the pizotifen-treated group (Fig. 5B). Taken together, the results of the present study indicated that the pizotifen-induced inhibitory effects on gastric cancer cell migration and invasion may be due to the inhibition of the Wnt/ $\beta$-catenin-EMT signaling pathway.

\section{Discussion}

Gastric cancer is one of the most serious malignant tumors; its mortality rate is lower only than that of lung cancer and liver cancer worldwide (1). Therefore, it has become a priority to explore the mechanism of the occurrence and development of gastric cancer in order to develop potential novel anti-cancer agents. In the present study, it was found that pizotifen could inhibit the viability, migration and invasion of MNK45 and AGS cells, as well as inducing apoptosis. Pizotifen is a serotonin antagonist that is primarily indicated for the prevention of recurrent migraine headaches. A number of studies have reported that serotonin can promote the growth of several types of cancer, including breast (25), prostate (26), colorectal (27), hepatocellular (28) and small-cell lung cancer (29). In addition, it has been reported that serotonin is involved in cancer cell migration, metastasis and angiogenesis (30). In some cases, antagonists of serotonin receptors have been successfully used to inhibit cancer cell growth $(31,32)$. The present study is the first to report the anti-tumor properties of pizotifen against gastric cancer cells. However, the effects of pizotifen on cell morphology and non-cancerous cells remain unclear, which is a limitation of the present study. In future studies, any potential anti-tumor properties of pizotifen should be further investigated in vivo and in clinical studies.

Aberrant activation of the Wnt signaling pathway is associated with the occurrence and development of tumors, and it has become the focus of studies seeking to therapeutic targets $(33,34)$. Therefore, drug development has been mainly focused on inhibiting the Wnt signaling cascade, and some of these drugs have since entered clinical trials $(35,36)$. Genome sequencing studies have revealed that the mutation of many components of the Wnt pathway are inherited in patients with gastric cancer, such as AXIN1, AXIN2 and $\beta$-catenin (37), suggesting that targeting Wnt has potential in the treatment 


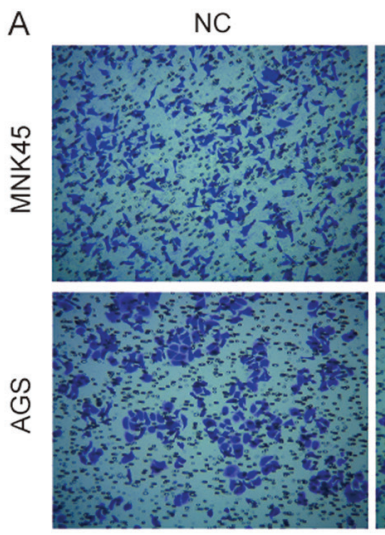

B

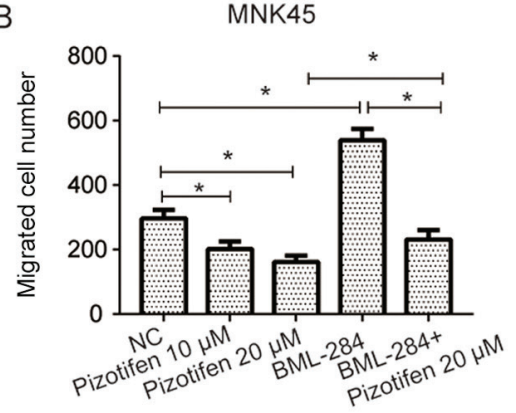

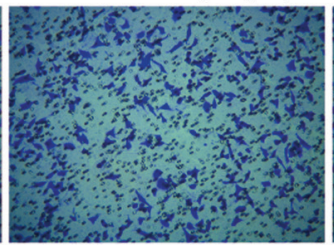
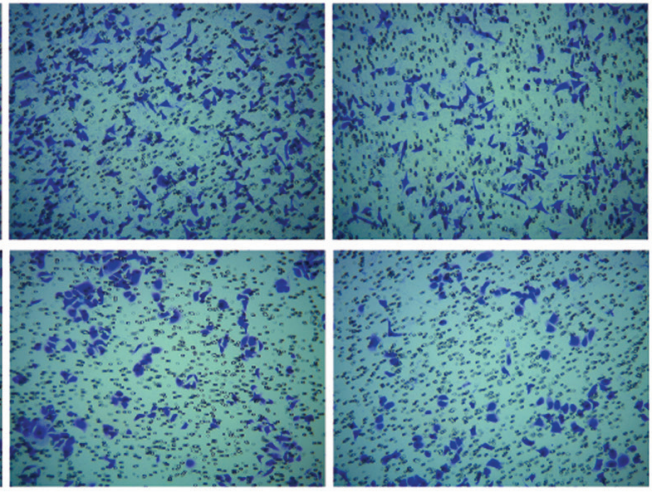

Pizotifen $(20 \mu \mathrm{M})$

BML-284

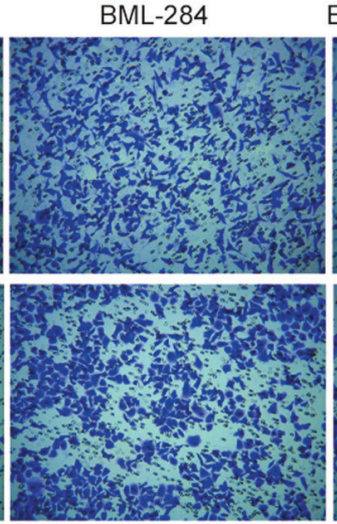

BML-284+ Pizotifen $(20 \mu \mathrm{M})$

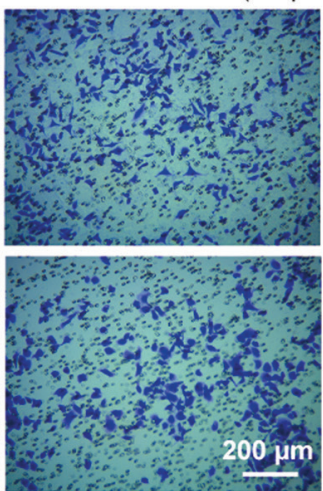

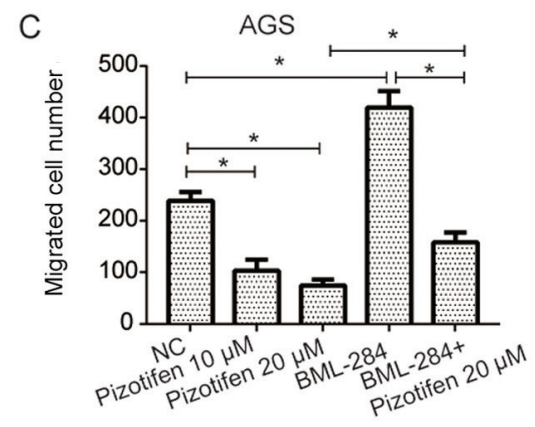

D

NC

Pizotifen $(10 \mu \mathrm{M})$

Pizotifen $(20 \mu \mathrm{M})$

BML-284

BML-284+ Pizotifen $(20 \mu \mathrm{M})$
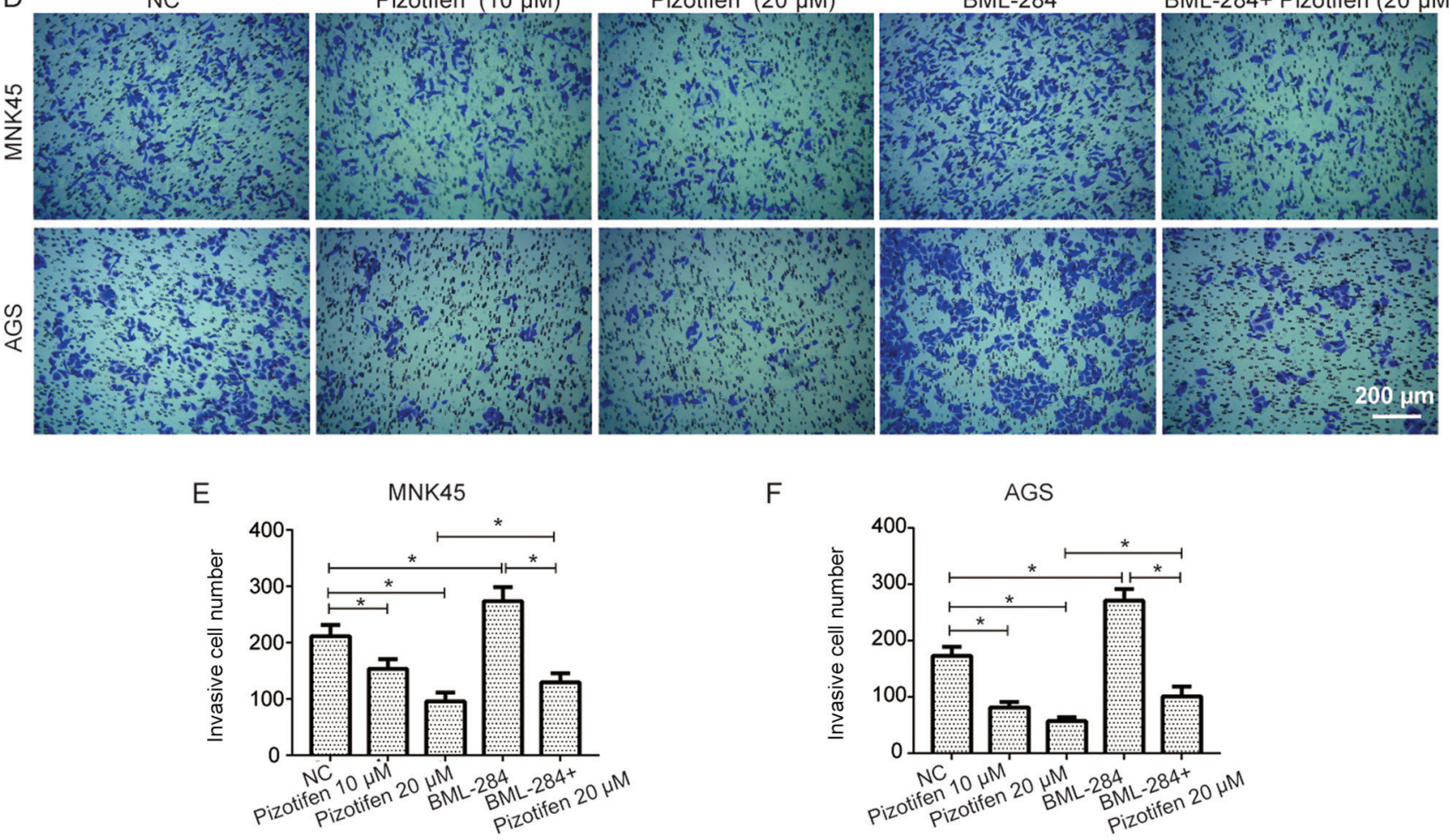

F

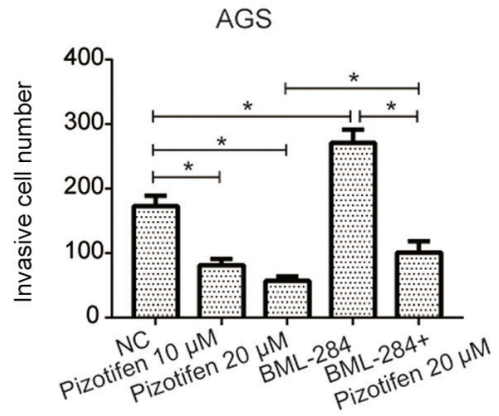

Figure 3. Pizotifen inhibits MNK45 and AGS cell migration and invasion. MNK45 and AGS cells were treated with two different concentrations of pizotifen $(10$ or $20 \mu \mathrm{M})$ or BML-284 $(10 \mu \mathrm{M})$ for $24 \mathrm{~h}$. A Transwell assay was carried out to assess the migratory and invasive abilities of MNK45 and AGS cells. (A) Representative images of MNK45 and AGS cell migration under each treatment condition. (B) Quantified data of MNK cell migration under each treatment condition. (C) Quantified data of AGS cell migration under each treatment condition. (D) Representative images of MNK45 and AGS cell invasion under each treatment condition. (E) Quantified data of MNK cell invasion under each treatment condition. (F) Quantified data of AGS cell invasion under each treatment condition. Scale bar, $200 \mu \mathrm{m}$. Data are expressed as the mean $\pm \mathrm{SD}$ from three independent experiments. "P<0.05 with comparisons indicted by lines. NC, negative control.

of gastric cancer. These data were verified in a mouse model of gastric cancer (38-40). This suggests that Wnt signaling is likely to be a driving factor in the occurrence of gastric cancer.
It was demonstrated in the present study that pizotifen could significantly downregulate the expression of Wnt3a and $\beta$-catenin in MNK45 and AGS cells. $\beta$-catenin is a 
A
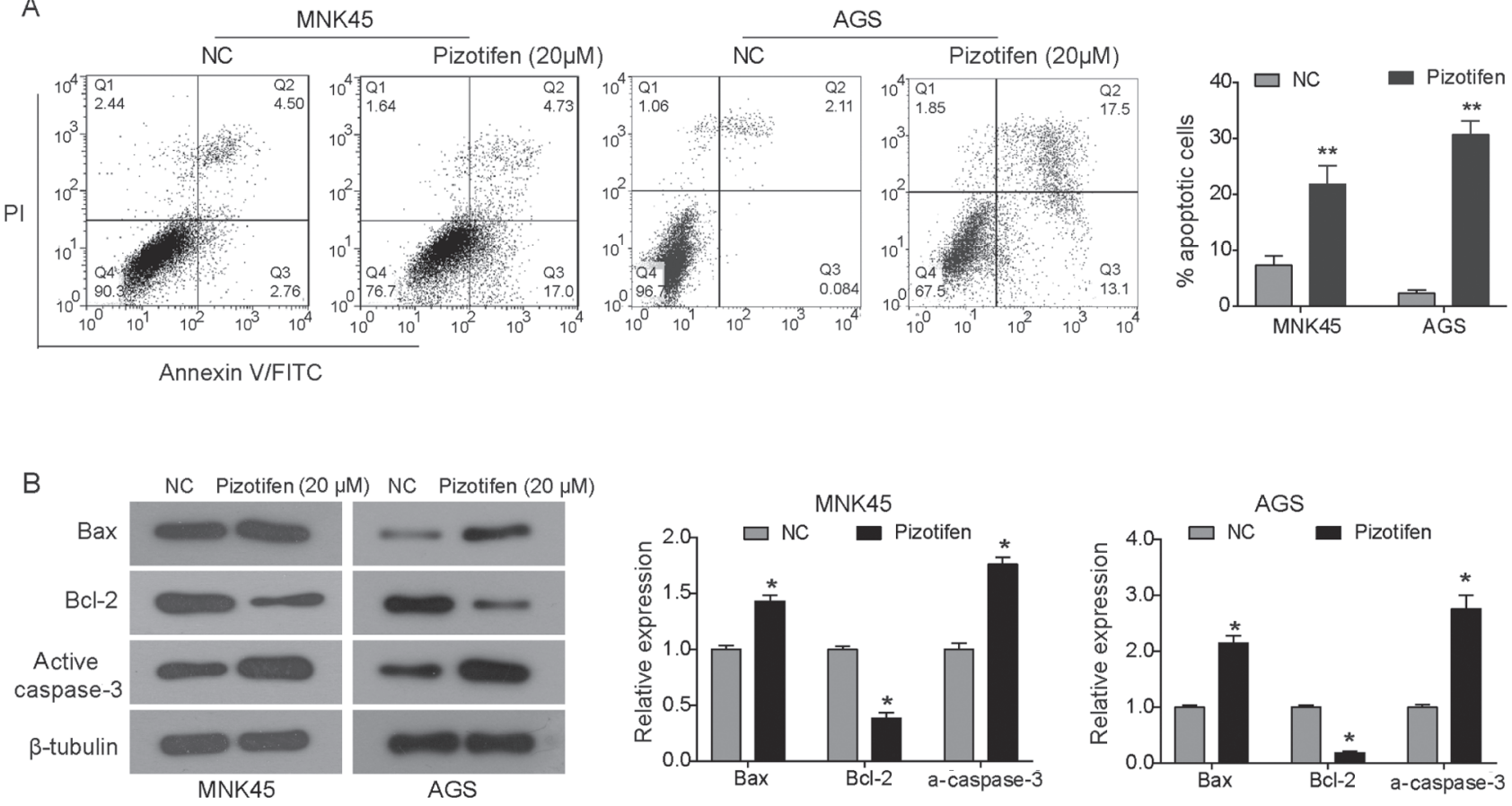

Figure 4. Pizotifen induces mitochondrial-mediated apoptosis of MNK45 and AGS cells. (A) MNK45 and AGS cells were treated with $20 \mu$ M pizotifen for $24 \mathrm{~h}$, and apoptosis was assessed using an Annexin V-FITC/propidium iodide assay coupled with flow cytometry. (B) Western blot analysis was performed to measure the expression of apoptosis-related proteins in MNK45 and AGS cells following pizotifen treatment for $48 \mathrm{~h}$. Data are expressed as the mean \pm SD from three independent experiments. ${ }^{*} \mathrm{P}<0.05,{ }^{* *} \mathrm{P}<0.01$ vs. NC. NC, negative control; PI, propidium iodide.
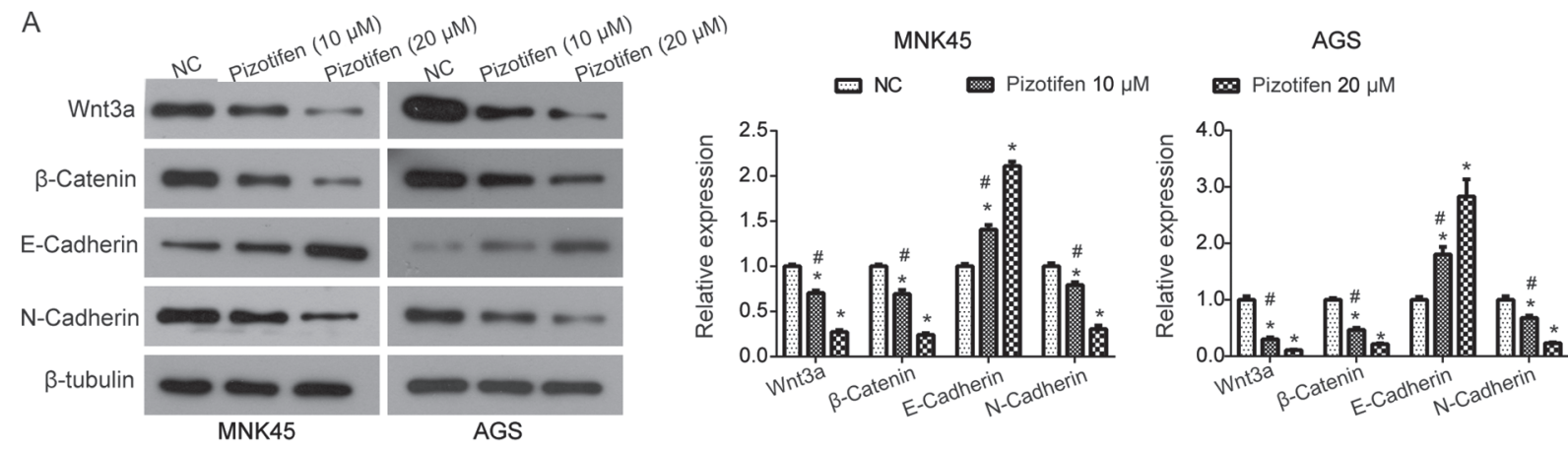

B
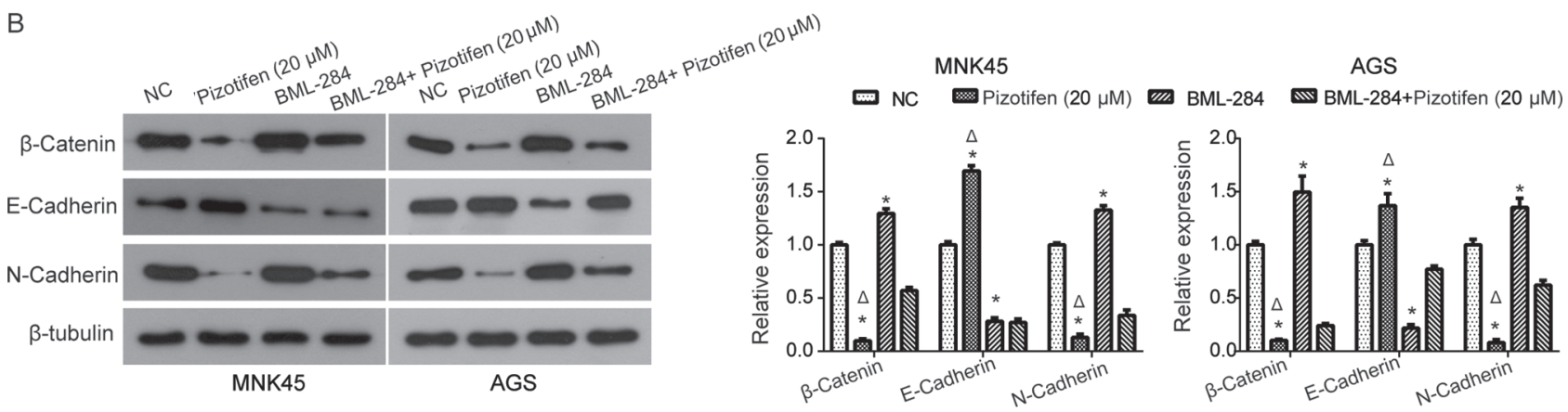

Figure 5. Pizotifen downregulates the Wnt/ $\beta$-catenin-EMT signaling pathway in MNK45 and AGS cells. (A) Western blot analysis was performed to detect the expression of proteins associated with the Wnt/ $\beta$-catenin-EMT signaling pathway in MNK45 and AGS cells following pizotifen treatment $(0,10$ or $20 \mu \mathrm{M})$. (B) The expression of proteins associated with the Wnt/ $\beta$-catenin-EMT signaling pathway in MNK45 and AGS cells following pizotifen (20 $\mu$ M) and/or BML-284 $(10 \mu \mathrm{M})$ treatment was assessed by western blotting. Data are expressed as the mean \pm SD from three independent experiments. "P<0.05 vs. NC; ${ }^{\#} \mathrm{P}<0.05$ vs. pizotifen $(20 \mu \mathrm{M}) ;{ }^{\wedge} \mathrm{P}<0.05$ vs. BML-284+pizotifen $(20 \mu \mathrm{M})$. NC, negative control; EMT, epithelial-mesenchymal transition.

multifunctional protein, which was initially found to bind to E-cadherin-binding protein and participate in cell adhesion (14). E-cadherin has been reported to be a key member of the Wnt signaling pathway, with transcriptional regulatory activity (15). It is hypothesized that the disruption of E-cadherin/ $\beta$-catenin complexes is involved in the malignant transformation of 
epithelial tumors (41). E-cadherin and N-cadherin are key markers for the EMT process, both of which serve essential roles in tumor metastasis. It was previously demonstrated that the downregulation of E-cadherin in gastric cancer could reduce the expression of the cadherin/catenin complex to increase cancer cell invasiveness (42). In the present study, it was found that pizotifen treatment in gastric cancer cell lines upregulated the expression of E-cadherin and downregulated the expression of $\mathrm{N}$-cadherin and $\beta$-catenin, an effect that was reversed by concomitant treatment with BML-284, a selective Wnt signaling activator. It was also observed in the present study that MNK45 and AGS cell migration and invasion, which were inhibited by pizotifen, were restored by simultaneous BML-284 treatment. Taken together, these observations suggested that inhibition of the Wnt/ $\beta$-catenin-EMT signaling pathway may be responsible for the anti-invasion properties of pizotifen.

In summary, the present study showed that pizotifen could inhibit the growth, migration and invasion of gastric cancer cells and induce cell apoptosis. The anti-cancer activity of pizotifen may be achieved by blocking the Wnt/ $\beta$-catenin-EMT signaling pathway. Based on these findings, pizotifen could potentially be used in a novel therapeutic approach for the treatment of gastric cancer, a notion which warrants further clinical evaluation. However, the precise mechanism of action of pizotifen will be explored further in a future study.

\section{Acknowledgements}

Not applicable.

\section{Funding}

No funding was received.

\section{Availability of data and materials}

The datasets used and/or analyzed during the present study are available from the corresponding author on reasonable request.

\section{Authors' contributions}

YJ, WW and XW designed the study. YJ and WW performed the experiments, and XW and JS analyzed the data. All authors interpreted the results, and produced and approved the final manuscript.

\section{Ethics approval and consent to participate}

Not applicable.

\section{Patient consent for publication}

Not applicable.

\section{Competing interests}

The authors declare that they have no competing interests.

\section{References}

1. Carlomagno N, Santangelo ML, Amato B, Calogero A, Saracco M, Cremone C, Miranda A, Dodaro C and Renda A: Total colectomy for cancer: Analysis of factors linked to patients' age. Int J Surg 12 (Suppl 2): S135-S139, 2014.

2. Strand MS, Lockhart AC and Fields R: Genetics of gastric cancer. Surg Clin North Am 97: 345-370, 2017.

3. Hamashima C: Current issues and future perspectives of gastric cancer screening. World J Gastroenterol 20: 13767-13774, 2014.

4. Chen W, Zheng R, Baade PD, Zhang S, Zeng H, Bray F, Jemal A, Yu XQ and He J: Cancer statistics in China, 2015. CA Cancer J Clin 66: 115-132, 2016.

5. Baker NE: Transcription of the segment-polarity gene wingless in the imaginal discs of drosophila, and the phenotype of a pupal-lethal wg mutation. Development 102: 489-497, 1988.

6. Croce JC and McClay DR: Evolution of the Wnt pathways. Methods Mol Biol 469: 3-18, 2008.

7. Clevers $H$ and Nusse $R$ : Wnt $/ \beta$-catenin signaling and disease. Cell 149: 1192-1205, 2012.

8. Rapp J, Jaromi L, Kvell K, Miskei G and Pongracz JE: WNT signaling - lung cancer is no exception. Respir Res 18: 167, 2017.

9. Byun T, Karimi M, Marsh JL, Milovanovic T, Lin F and Holcombe RF: Expression of secreted Wnt antagonists in gastrointestinal tissues: Potential role in stem cell homeostasis. J Clin Pathol 58: 515-519, 2005.

10. Barker N, Huch M, Kujala P, van de Wetering M, Snippert HJ, van Es JH, Sato T, Stange DE, Begthel H, van den Born M, et al: Lgr5(+ve) stem cells drive self-renewal in the stomach and build long-lived gastric units in vitro. Cell Stem Cell 6: 25-36, 2010.

11. Wang K, Yuen ST, Xu J, Lee SP, Yan HH, Shi ST, Siu HC, Deng S, Chu KM, Law S, et al: Whole-genome sequencing and comprehensive molecular profiling identify new driver mutations in gastric cancer. Nat Genet 46: 573-582, 2014.

12. Cristescu R, Lee J, Nebozhyn M, Kim KM, Ting JC, Wong SS, Liu J, Yue YG, Wang J, Yu K, et al: Molecular analysis of gastric cancer identifies subtypes associated with distinct clinical outcomes. Nat Med 21: 449-456, 2015.

13. Nagaoka T, Karasawa H, Turbyville T, Rangel MC, Castro NP, Gonzales M, Baker A, Seno M, Lockett S, Greer YE, et al: Cripto-1 enhances the canonical Wnt/ $\beta$-catenin signaling pathway by binding to LRP5 and LRP6 co-receptors. Cell Signal 25: 178-189, 2013.

14. Garinis GA, Spanakis NE, Menounos PG, Manolis EN and Peros G: Transcriptional impairment of beta-catenin/E-cadherin complex is not associated with beta-catenin mutations in colorectal carcinomas. Br J Cancer 88: 206-209, 2003.

15. Kikuchi A, Yamamoto H, Sato A and Matsumoto S: New insights into the mechanism of Wnt signaling pathway activation. Int Rev Cell Mol Biol 291: 21-71, 2011.

16. Micalizzi DS, Farabaugh SM and Ford HL: Epithelial-mesenchymal transition in cancer: Parallels between normal development and tumor progression. J Mammary Gland Biol Neoplasia 15: 117-134, 2010.

17. Peng Z, Wang CX, Fang EH, Wang GB and Tong Q: Role of epithelial-mesenchymal transition in gastric cancer initiation and progression. World J Gastroenterol 20: 5403-5410, 2014.

18. Yue H, Tang B, Zhao Y, Niu Y, Yin P, Yang W, Zhang Z and Yu P: MIR-519d suppresses the gastric cancer epithelial-mesenchymal transition via Twist 1 and inhibits Wnt/ $\beta$-catenin signaling pathway. Am J Transl Res 9: 3654-3664, 2017.

19. Cho ES, Kang HE, Kim NH and Yook JI: Therapeutic implications of cancer epithelial-mesenchymal transition (EMT). Arch Pharm Res 42: 14-24, 2019.

20. Fuchs R, Schwach G, Stracke A, Meier-Allard N, Absenger M, Ingolic E, Haas HS, Pfragner R and Sadjak A: The anti-hypertensive drug prazosin induces apoptosis in the medullary thyroid carcinoma cell line TT. Anticancer Res 35: 31-38, 2015.

21. Lin OA, Karim ZA, Vemana HP, Espinosa EV and Khasawneh FT: The antidepressant $5-\mathrm{HT}_{2 \mathrm{~A}}$ receptor antagonists pizotifen and cyproheptadine inhibit serotonin-enhanced platelet function. PLoS One 9: e87026, 2014.

22. Speight TM and Avery GS: Pizotifen(BC-105): A review of its pharmacological properties and its therapeutic efficacy in vascular headaches. Drugs 3: 159-203, 1972. 
23. Ahmadi AA, Shadifar M, Ataee R, Vaillancourt C, Ataee A, Oufkir T and Jafari-Sabet M: The serotonin $5-\mathrm{HT}_{2 \mathrm{~A}}$ receptor antagonist ritanserin induces apoptosis in human colorectal cancer and acts in synergy with curcumin. Int Biol Biomed J 1: 56-65, 2015.

24. Liu J, Wu X, Mitchell B, Kintner C, Ding S and Schultz PG: A small-molecule agonist of the Wnt signaling pathway. Angew Chem Int Ed Engl 44: 1987-1990, 2005.

25. Cheng YY, Yu J, Wong YP, Man EP, To KF, Jin VX, Li J, Tao Q, Sung JJ, Chan FK and Leung WK: Frequent epigenetic inactivation of secreted frizzled-related protein 2 (SFRP2) by promoter methylation in human gastric cancer. Br J Cancer 97: 895-901, 2007.

26. Hanaki H, Yamamoto H, Sakane H, Matsumoto S, Ohdan H, Sato A and Kikuchi A: An anti-Wnt5a antibody suppresses metastasis of gastric cancer cells in vivo by inhibiting receptor-mediated endocytosis. Mol Cancer Ther 11: 298-307, 2012.

27. Ataee R, Ajdary S, Zarrindast M, Rezayat $M$ and Hayatbakhsh MR: Anti-mitogenic and apoptotic effects of 5-HT1B receptor antagonist on HT29 colorectal cancer cell line. J Cancer Res Clin Oncol 136: 1461-1469, 2010.

28. Soll C, Riener MO, Oberkofler CE, Hellerbrand C, Wild PJ, DeOliveira ML and Clavien PA: Expression of serotonin receptors in human hepatocellular cancer. Clin Cancer Res 18: 5902-5910, 2012.

29. Vicentini LM, Cattaneo MG and Fesce R: Evidence for receptor subtype cross-talk in the mitogenic action of serotonin on human small-cell lung carcinoma cells. Eur J Pharmacol 318: 497-504, 1996.

30. Soll C, Jang JH, Riener MO, Moritz W, Wild PJ, Graf R and Clavien PA: Serotonin promotes tumor growth in human hepatocellular cancer. Hepatology 51: 1244-1254, 2010.

31. Dizeyi N, Hedlund P, Bjartell A, Tinzl M, Austild-Taskén K and Abrahamsson PA: Serotonin activates MAP kinase and PI3K/Akt signaling pathways in prostate cancer cell lines. Urol Oncol 29: 436-445, 2011.

32. Siddiqui EJ, Shabbir MA, Mikhailidis DP, Mumtaz FH and Thompson CS: The effect of serotonin and serotonin antagonists on bladder cancer cell proliferation. BJU Int 97: 634-639, 2006.

33. Hirokawa Y, Yip KH, Tan CW and Burgess AW: Colonic myofibroblast cell line stimulates colonoid formation. Am J Physiol Gastrointest Liver Physiol 306: G547-G556, 2014.
34. Byun MR, Hwang JH, Kim AR, Kim KM, Hwang ES, Yaffe MB and Hong JH: Canonical Wnt signalling activates TAZ through PP1A during osteogenic differentiation. Cell Death Differ 21: 854-863, 2014.

35. Bu G, Lu W, Liu CC, Selander K, Yoneda T, Hall C, Keller ET and Li Y: Breast cancer-derived Dickkopf1 inhibits osteoblast differentiation and osteoprotegerin expression: Implication for breast cancer osteolytic bone metastases. Int J Cancer 123: 1034-1042, 2008

36. He S, Lu Y, Liu X, Huang X, Keller ET, Qian CN and Zhang J: Wnt3a: Functions and implications in cancer. Chin J Cancer 34 : 554-562, 2015.

37. Pan KF, Liu WG, Zhang L, You WC and Lu YY: Mutations in components of the Wnt signaling pathway in gastric cancer. World J Gastroenterol 14: 1570-1574, 2008.

38. Kahn M: Can we safely target the WNT pathway? Nat Rev Drug Discov 13: 513-532, 2014

39. Mook RA Jr, Wang J, Ren XR, Chen M, Spasojevic I, Barak LS, Lyerly HK and Chen W: Structure-activity studies of $W n t / \beta$-catenin inhibition in the niclosamide chemotype: Identification of derivatives with improved drug exposure. Bioorg Med Chem 23: 5829-5838, 2015.

40. Steinhart Z, Pavlovic Z, Chandrashekhar M, Hart T, Wang X, Zhang X, Robitaille M, Brown KR, Jaksani S, Overmeer R, et al: Corrigendum: Genome-wide CRISPR screens reveal a Wnt-FZD5 signaling circuit as a druggable vulnerability of RNF43-mutant pancreatic tumors. Nat Med 23: 1384, 2017.

41. Kim H, Yoo SB, Sun P, Jin Y, Jheon S, Lee CT and Chung JH: Alteration of the E-cadherin/ $\beta$-catenin complex is an independent poor prognostic factor in lung adenocarcinoma. Korean J Pathol 47: 44-51,2013.

42. Cheng XX, Wang ZC, Chen XY, Sun Y, Kong QY, Liu J, Gao X, Guan HW and Li H: Frequent loss of membranous E-cadherin in gastric cancers: A cross-talk with Wnt in determining the fate of beta-catenin. Clin Exp Metastasis 22: 85-93, 2005.

(i) (-) This work is licensed under a Creative Commons Attribution-NonCommercial-NoDerivatives 4.0 International (CC BY-NC-ND 4.0) License. 